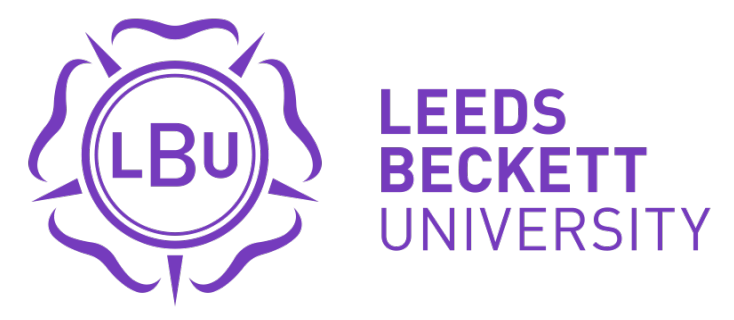

Citation:

Hynan, A and Goldbart, $\mathrm{J}$ and Murray, $\mathrm{J}$ (2015) A grounded theory of Internet and social media use by young people who use augmentative and alternative communication (AAC). Disability and rehabilitation, 37 (17). 1559 - 1575. ISSN 0963-8288 DOI: https://doi.org/10.3109/09638288.2015.1056387

Link to Leeds Beckett Repository record:

https://eprints.leedsbeckett.ac.uk/id/eprint/1715/

Document Version:

Article (Accepted Version)

The aim of the Leeds Beckett Repository is to provide open access to our research, as required by funder policies and permitted by publishers and copyright law.

The Leeds Beckett repository holds a wide range of publications, each of which has been checked for copyright and the relevant embargo period has been applied by the Research Services team.

We operate on a standard take-down policy. If you are the author or publisher of an output and you would like it removed from the repository, please contact us and we will investigate on a case-by-case basis.

Each thesis in the repository has been cleared where necessary by the author for third party copyright. If you would like a thesis to be removed from the repository or believe there is an issue with copyright, please contact us on openaccess@leedsbeckett.ac.uk and we will investigate on a case-by-case basis. 


\title{
A grounded theory of Internet and social media use by young people who use Augmentative and
}

\section{Alternative Communication (AAC)}

Amanda Hynan ${ }^{1}$,Juliet Goldbart ${ }^{2}$ and Janice Murray ${ }^{2}$

${ }^{1}$ Faculty of Health and Social Sciences, School of Social, Psychological and Communication Sciences, Leeds Beckett University, Leeds, UK amandahynan@gmail.com

${ }^{2}$ Research Institute for Health and Social Change, Manchester Metropolitan University, Manchester, UK

\begin{abstract}
Purpose: This paper presents a conceptual grounded theory for how young people with a diagnosis of cerebral palsy who use augmentative and alternative communication (AAC), perceive using the Internet and social media. The aims of the research were to understand and contextualise their perceptions of access and use and explore implications for self-representation and social participation; to date literature on this topic is limited.
\end{abstract} Method: A constructivist grounded theory research approach concurrently collected and analysed interview data from 25 participants (aged 14-24 years) who use AAC and additional sources. Results: A conceptual grounded theory was developed around an emergent core category that showed young people who use AAC have a clear desire to use the Internet and social media. This was underpinned by eight supporting categories: reported use, described support, online challenges, access technology, speech generating device issues, self-determination, self-representation and online social ties. Conclusion: The conceptual grounded theory supports understanding of facilitators and challenges to use of the Internet and social media by young people with a diagnosis of cerebral palsy who use AAC. The grounded theory illustrates how the desire to use the Internet and social media is based upon perceived benefits for enriching social relationships and enhancing opportunities for selfrepresentation and self-determination that are synonymous with identified antecedents for community-based social inclusion. Some of the participants are engaging with the Internet and social media through collaborative practice and the implications for how this phenomenon may impact on orthographic literacy and the personal care workforce are raised.

\section{Implications for Rehabilitation}

- This research has created a conceptual grounded theory framework to support a deeper understanding of the perspectives of young people (with a diagnosis of cerebral palsy) who use augmentative and alternative

Hynan, A., Goldbart, J. \& Murray, J. (2015). A grounded theory of Internet and social media use by young people who use augmentative and alternative communication (AAC). Disability and Rehabilitation, early online. DOI 10.3109/09638288.2015.1056387 
communication (AAC) in relation to engaging with the Internet and social media. The conceptual framework illustrates factors that facilitate and/or challenge use of the Internet and social media and can be used to guide future research and funding organisations.

- The core message of the grounded theory is that the young people who use AAC have a desire to engage with the Internet and social media due to perceived benefits for enriching social relationships and enhancing opportunities for self-representation and self-determination.

- The paper illustrates how these digital communication benefits are synonymous with identified antecedents for perceptions of community-based social inclusion.

- Participants describe collaborating with others to use the Internet and social media which may have implications for the development of orthographic literacy and the personal care workforce.

\section{Introduction}

Augmentative and alternative communication (AAC) is a scientific and clinical discipline that seeks to support people with significant communication disabilities to express themselves. The desire to harness technology to support people has led to the development of computer based speech generating devices (SGDs), also known as voice output communication aids (VOCAs) in the United Kingdom. The challenge has always been to balance the enormous potential of computer technology against individual characteristics such as motor, sensory and perceptual skills, as well as cognitive and linguistic demands [1]. As society is hurtling through a digital communication revolution, using technology to communicate has become an accepted and essential aspect of most people's lives.

This paper presents a conceptual grounded theory built on interview-based data from 25 young people with a diagnosis of cerebral palsy, a motor impairment that can restrict the use of natural speech, who use AAC. To date there is limited understanding of how the Internet and social media are experienced by young people who use AAC. Social media is a term which describes Internet-based applications that allow users to create, exchange and modify content through interactive platforms within mobile technologies such as tablet and smart phone devices. It is important both morally and legally that the views of young people with physical disabilities and communication challenges are sought on issues that concern their lives. Research to date often focuses on those who are verbally articulate or relies on adult/caregiver perceptions [2-6]. 
To date, research about Internet and social media use by people who use AAC has been spread across different countries and is very limited. An Internet and social media focused intervention project in Australia included qualitative interviews with 15 participants with physical disabilities, five of whom had communication disabilities and one who used AAC [7-9]. These researchers found that the extent and frequency of Internet use was lower than typically developing peers; friends were the main online contacts and the digital skills of parents, siblings and friends had significant influence on use. Garcia et al. [10] carried out questionnaire-based research in a special school environment in Spain with 30 children (mean age 13.3 years) about their use of computers and found that they were keen to use technology but there was a lack of training, financial support and personalised assessment to support access. Several small scale studies have interviewed adults who use AAC and demonstrated mobile technologies offer perceived benefits for leisure opportunities and peer-based support networks, as well as improving opportunities to be understood more clearly [11-14].

\section{Self-representation and identity within online environments}

A consistent observation about young people is the attention they pay to the presentation of self; Livingstone suggested social media sites (due to the convergence of multimedia such as email, music, photographs, website linking etc.) offer young people opportunities to construct their presentation of self in ways not seen before [15]. Communicating through social media may address some of the face-to-face communication challenges that can impact on the expression of self-identity by people who use AAC [16]. Literature has shown people who use AAC can experience time pressures in fast moving conversations [17] and have unequal turn-taking opportunities [18-20] which can in turn limit opportunities to construct personal narratives and express humour $[16,21,22]$. Waller [22] discussed the importance of interactional conversation to share life narratives and develop personal identity and stated that people who use AAC often rely on close communication partners to tell stories for them. Two adults who use AAC have written personal accounts that indicate the use of mobile technology has improved communication opportunities to express themselves [23, 24]. However, a major challenge for engaging within predominantly text-based Internet and social media environments for people who use AAC is low levels of orthographic literacy [25, 26] and language domain difficulties [27]. Many forms of AAC address these issues by utilising symbol-based vocabulary systems; Sundqvist and Ronnberg [28] ran an intervention study to support children to use symbol-based email and found using this medium helped reduce time pressure and alleviate unequal turn-taking.

Hynan, A., Goldbart, J. \& Murray, J. (2015). A grounded theory of Internet and social media use by young people who use augmentative and alternative communication (AAC). Disability and Rehabilitation, early online. DOI 10.3109/09638288.2015.1056387 
Social media is influencing friendship maintenance by allowing people to connect and engage in new ways that Vallor suggested are yet to be fully understood or realised [29]. The growing popularity of the Internet and social media among young people within Western societies offers integration opportunities within social, political, economic and cultural networks [30]. A way of envisaging relationships within offline and online environments is to consider social ties; a term associated with social capital theory which is generally associated with the individual work of three people, Pierre Bourdieu, James Coleman and Robert Putnam. Social capital can be defined as the strength and maintenance of social ties which can be conceptualised as bonding (enriching existing social ties) or bridging (creating new social ties). Social capital is an influential concept that has gained ground over the latter half of the last century and emphasises the reciprocal nature of social relationships and the importance this has for achieving mutual goals, although it is not without critics. Holt suggested it can have neoliberal undertones that reinforce disadvantage that is embedded within the everyday practices of social networks $[31,32]$. The concept of social capital has been utilised by researchers when looking at the value of the Internet and social media in regard to social ties [33]. Social media may help support bonding social capital by enriching social ties [34]. Recent work looking at Facebook from the perspective of social capital theory led to Ellison et al. [35] coining a new term 'maintained' social capital which they felt expressed how Facebook helped sustain contact between networks of old friends.

Young people share a wealth of candid and intimate information online about interests, extracurricular social activities and family dynamics within virtual communities, which support, reinforce and enrich their offline social relationships [36, 37]. Adolescents are not necessarily using social media to replace face-to-face communication but use it to add a significant dimension to existing relationships [38], often finding it easier to be themselves online. Digital exclusion is a potential area of concern [30], and researchers must take a nuanced approach to look deeper than material access in order to understand the social and cultural influences that drive the use of, and engagement with, online technology.

Young people with disabilities are likely to have the same aspirations for friendship, participation and recognition as their non-disabled peers $[39,40]$ but those with developmental conditions such as cerebral palsy often have lower social participation opportunities due to the ways that individual mobility and communication skills interact with environmental barriers [41-46]. Bartorowicz et al. [46] interviewed 8 school-aged children (7 had a diagnosis of cerebral palsy) who used AAC and their parents about participation opportunities. The 
children identified a friend as someone who was easy to talk to and made them feel happy. The parents identified that their children valued communication and social interaction opportunities but had very limited contact with friends outside of school activities.

Mobile communication technologies have been reported to increase societal participation by supporting social networks for people who use AAC [47]. Grace et al. [7] found training young people who use AAC to use the Internet and social media increased opportunities for social participation. All young people, including those who use AAC, strive to establish intimate friendships and access emotional support during adolescence [37, 48-50]. The current research sought to explore how being online may address social participation factors by offering opportunities to build, enrich and maintain social ties and relationships beyond the confines of temporal, spatial and physical challenges $[8,50,51]$. Kirk noted many people with physical disabilities find it difficult to keep in touch with acquaintances as they move through life and points of transition can mean the end of valued relationships [52]. Very little is reported about the value young people who use AAC may or may not place on using the Internet and social media in terms of their perceptions of social ties and participation.

\section{Traditional SGDs and mobile technologies}

Being able to access the Internet and social media through traditional SGDs is a relatively new phenomenon for many people who rely on AAC; early integrated devices started to appear in 2007. The focus of traditional SGDs had been on face-to-face communication support but they have evolved from bulky dedicated appliances into sleek lightweight devices that can connect with the Internet and social media. Many software companies have also developed the use of symbolised vocabulary within social media sites. Mainstream mobile technologies have also embraced the concept of AAC with the development of voice output communication Apps [53]. This has created a paradigm shift that has been described as the democratisation of AAC due to the impact of increased choice, lowered costs and raised awareness of AAC [54, 55]. Much has been written over the last few years about the symbiosis of these two areas $[1,55,56,57]$ as integration has created opportunities for people who use AAC to engage with the Internet and social media in new and exciting ways. However, there are legitimate concerns in areas such as the robustness of design, ongoing support for mobile technologies compared to traditional equipment, access problems and concerns over quality and possible abandonment of AAC if Apps fail to meet expectations [53, 57]. Significant technical, policy and financial barriers have been identified for people who use AAC in terms of using the Internet [57] and simply supplying technology will not necessarily overcome participation barriers $[58,59]$. 
An optimistic view of the future has been painted by Shane et al. [55] who propose that advances in technology may produce personalised solutions for alternative access for people who use AAC; for example, ongoing progress with eye-gaze technology, Radio Frequency Identification (RFID, wireless non-contact technology used to transfer data by the recognition of tags attached to objects), the commitment to a global public inclusive infrastructure (GPII $)^{1}$, camera detection/microphones which will be able to use any type of motion to control a computer, 'crowd sourcing' (human and computer based assistants within cloud technology environments) and Near Field Communication (NFC, allowing devices to connect when near each other). The other side of this bright view of the future was discussed within the 2012 State of the Science conference in AAC: AAC-RERC final report [60] where it was argued technical innovation may extend disability in novel ways; the rise of voice controlled technology and movement sensor operating systems may disadvantage people with communication and physical disabilities.

It is imperative that niche populations of young people are included in research so that factors that are specific to their use of the Internet and social media are revealed. To date, there is a lack of conceptual frameworks from which to consider the use of the Internet and social media for people who use AAC. It is hoped the presentation of the conceptual grounded theory developed by this research will guide future research and funding endeavours in the absence of a wider body of research within this area.

\section{Research aims}

The aims of the current research were to collate the views of young people who use AAC to build a conceptual model about their use of the Internet and social media, their perceptions of accessibility and the potential impact upon attitudes to self-representation and social ties.

\section{Methodology}

\section{Ethical approval}

Prior to beginning recruitment, ethical approval was granted from the sponsoring university's faculty ethics committee.

\footnotetext{
${ }^{1} \mathrm{GPII}$ is a Raising the Floor project (www.raisingthefloor.org) dedicated to making the Internet accessible to everyone. It is a worldwide initiative made up of organisations from academia, industry, consumers, nongovernment organisations, activists etc.
}

Hynan, A., Goldbart, J. \& Murray, J. (2015). A grounded theory of Internet and social media use by young people who use augmentative and alternative communication (AAC). Disability and Rehabilitation, early online. DOI 10.3109/09638288.2015.1056387 
The aims of the research to collect rich data on individual experiences of using the Internet and social media meant a qualitative research approach was the most appropriate [61]. A social constructivist approach that ontologically comprehends reality to be a social construct and epistemologically regards understanding of this as being jointly created was considered the best fit for the current study. Any emergent knowledge would rest on the differing, and yet shared, historical, contextual and cultural perspectives that the current parties would bring to the research process [62]. Charmaz's constructivist version of grounded theory [63-66] which recognises how researcher preconceptions intercept with participant data to co-construct an empirical reality was chosen due to the lack of prior knowledge on the topic meaning theory generation was important. This approach accommodated taking an inductive approach that returned to the data deductively to create an understanding of the lived experience of using the Internet and social media.

\section{Recruitment and participant information}

Recruitment targeted young people, aged 14-24 who used AAC and had experience of using the Internet and social media, by distributing project information material through specialist educational settings (one of which had an adult residential department) and AAC-related organisations. Inclusion criteria required participants to be over 14 years old, use a high-tech form of AAC and have access to the Internet and social media. Young people who needed support to access the Internet and social media due to cognitive or orthographic literacy limitations were not excluded. Twenty-five young people with a diagnosis of cerebral palsy (13 male, 12 female, mean age 20.04 years) who used SGDs contributed to the research (see Table 1). All had physical disabilities and used wheelchairs for mobility but differed in their language, orthographic literacy and computer skills leading to varying access methods for SGDs or mainstream mobile technologies. One participant (Caroline) had a hearing impairment and Mary and Keith had some naturally spoken speech but predominantly used AAC.

Hynan, A., Goldbart, J. \& Murray, J. (2015). A grounded theory of Internet and social media use by young people who use augmentative and alternative communication (AAC). Disability and Rehabilitation, early on- 
Hynan, A., Goldbart, J. \& Murray, J. (2015). A grounded theory of Internet and social media use by young people who use augmentative and alternative communication (AAC). Disability and Rehabilitation, early online. DOI 10.3109/09638288.2015.1056387 
Table 1: Demographic information

Participants who used AAC

\begin{tabular}{|c|c|c|c|}
\hline Pseudonym & Age & Male/Female & Type of AAC used, method of access and level of orthographic literacy \\
\hline Peter & 17 & M & SGD, head switches on wheelchair, moderate orthographic literacy \\
\hline Mary & 17 & $\mathrm{~F}$ & Small amount of natural speech, SGD, Direct access, moderate orthographic literacy \\
\hline Caroline & 21 & $\mathrm{~F}$ & SGD, head switches mounted on wheelchair, orthographic literacy, sign language \\
\hline Nicholas & 23 & M & SGD, direct access, no orthographic literacy \\
\hline Carol & 19 & $\mathrm{~F}$ & SGD, direct access, preferred using Makaton, emerging orthographic literacy \\
\hline Georgie & 19 & $\mathrm{~F}$ & Eye Gaze (E-tran frame, SGD not wanted), emerging orthographic literacy \\
\hline Fiona & 23 & $\mathrm{~F}$ & SGD, head switches on wheelchair, no orthographic literacy \\
\hline Moira & 22 & $\mathrm{~F}$ & SGD, direct access, orthographic literacy \\
\hline Olivia & 21 & $\mathrm{~F}$ & SGD, head switches on wheelchair, orthographic literacy \\
\hline Maddy & 20 & $\mathrm{~F}$ & SGD, direct access, orthographic literacy unknown \\
\hline Xavier & 19 & M & SGD, head switches on wheelchair, orthographic literacy \\
\hline Simon & 21 & M & SGD, head switches on wheelchair, no orthographic literacy \\
\hline Keith & 19 & M & SGD, direct access, orthographic literacy \\
\hline Davey & 21 & M & SGD, direct access, no orthographic literacy \\
\hline Ben & 14 & M & SGD, direct access, orthographic literacy \\
\hline Harriet & 22 & $\mathrm{~F}$ & Alphabet board, orthographic literacy, (SGD broken) \\
\hline Will & 19 & M & SGD, head switches on wheelchair, orthographic literacy \\
\hline Kevin & 21 & $\mathrm{M}$ & SGD, head switches on wheelchair, no orthographic literacy \\
\hline Faith & 21 & $\mathrm{~F}$ & SGD, direct access no orthographic literacy \\
\hline Richard & 21 & M & SGD, direct access, no orthographic literacy \\
\hline Jack & 20 & M & SGD, direct access, emerging orthographic literacy \\
\hline Erica & 21 & $\mathrm{~F}$ & SGD, head mouse camera, orthographic literacy \\
\hline Nancy & 21 & $\mathrm{~F}$ & SGD, head mouse camera, orthographic literacy \\
\hline Ken & 21 & M & iPad, direct access, some speech, orthographic literacy \\
\hline Sean & 19 & M & SGD, direct access, orthographic literacy \\
\hline
\end{tabular}

SGD = speech generating device; Makaton = http://www.makaton.org/; orthographic = differentiates literacy as participants use individual symbolised vocabulary systems; E-tran = See Figure 1 for full explanation 


\section{Procedure}

Individual face-to-face semi-structured interviews were chosen as the best way to explore the participants' views but also to add deeper understanding of AAC-mediated face-to-face conversations and contextualize the potential impact of online communication environments. The participants were seen within their educational settings and interviews ranged from 30 minutes to 2 hours. These were transcribed verbatim and used the following transcription protocol outlined by von Tetzchner and Basil [67]: the meaning of non-verbal communication is marked by single quotation marks with a description in brackets, e.g. 'yes' (nods head); SGD communication is within speech parenthesis and italicised e.g. "Yes"; naturally spoken speech is italicised. Data from a participant who used an alphabet board to finger spell answers has been underlined and hyphenated, e.g. s-p-e-l-l-e-d w-o-r-d-s and another participant's data is clearly marked as being submitted via an online blog that she specifically created for the project as it was not possible to meet in person. The interviews were guided by universal themes commonly found within Internet focused literature and refined for AAC from data collected in a pilot investigation. Key themes were: how participants felt about using the Internet and social media; types of access methods used; types of content used; self-representation choices and types of online social ties (a topic guide is available from the lead author on request).

\section{Data collection and analysis}

Concurrent data collection and analysis followed the constructivist grounded theory approach developed by Charmaz [64-66]. In line with this approach other data sources were targeted (see Table 2) as it was not always possible for emergent issues to be explained by participants, for example, the power limitations of a SGD prevented text use and had to be explained by the Head of Technology.

\section{Table 2: Summary of data sources}

\begin{tabular}{|l|l|}
\hline Type of data & Quantity \\
\hline Interview transcripts with people who use AAC & 24 \\
\hline $\begin{array}{l}\text { Interview data from heads of technology in two special colleges, one } \\
\text { quality assurance manager in a special school and adult residential } \\
\text { centre }\end{array}$ & 3 \\
\hline Participant demonstrations of using social media & 5 \\
\hline
\end{tabular}




\begin{tabular}{|l|l|}
\hline $\begin{array}{l}\text { Internet blog created by a participant who could not be seen in } \\
\text { person. Email questions sent by researcher as a guide. }\end{array}$ & 1 \\
\hline Video recordings of interviews & 22 \\
\hline Policy documents on social media use in educational settings & 3 \\
\hline Field notes & $\begin{array}{l}\text { Several notebooks and voice } \\
\text { memos }\end{array}$ \\
\hline
\end{tabular}

The additional data came from: three policy guidance documents within settings, five demonstrations of use by participants, numerous field notes, three interviews with key members of staff and non-verbal communication analysis of 22 videos made during participant interviews (see Table 3).

Table 3: Demographic information Additional participants

\begin{tabular}{|l|l|l|}
\hline Role & Gender & Setting \\
\hline Head of technology department 1 & Male & Specialist college \\
\hline Head of technology department 2 & Male & Specialist college \\
\hline Quality assurance manager & Female & Specialist educational setting \\
\hline
\end{tabular}

Sometimes this data emerged during an interview if the member of staff was present and sometimes the data was pursued post interview in order to illuminate an issue that had been raised by a participant but not understood by the first researcher (See Figure 1). 
Figure 1: Sequence of data collection occasions over eighteen months

1) Solo interview, SGD broken, yes/no questions. Father supports

2) Solo interview, some speech, SGD used. No communication partner support

3) Group meeting five participants, all used SGDs. One participant had support. Speech and language therapist and specialist teaching assistant present

4) Four individual interviews. SGDs used in three (one with Makaton signing). Eye transfer frame ${ }^{2}$ used in fourth interview. Speech therapist supports all. Personal assistant supports one. Quality assurance manager interview. Policy documents

5) Four solo interviews (two seen previously in group, see occasion 2). SGDs used by all. Specialist teaching assistant supports two interviews.

6) First participant seen again (see occasion 1) for second interview as SGD fixed. Pre-prepared answers from pre-sent email questions. Father supports interview.

7) Solo interview, SGD used. Teaching assistant supports interview.

8) Two interviewees seen together as dyad. One used SGD, other used alphabet board. Two speech and language therapists support interview.

9) Two solo interviews (previously seen in group, occasion 2). SGDs used. No communication partner support.

10) Four solo interviews (seen simultaneously as group in class). SGDs used. Speech and language therapist and two personal assistants support interview. Solo interview with Head of technical department. Policy documentation provided.

11) Blog data received

12) Four solo interviews. Three use SGDs, one uses iPad. Head of technical department supports first interview and takes part in solo interview. Policy documents provided.

Data analysis was carried out through a coding process outlined by Charmaz [64] of initial, focused and theoretical coding and supported by memo writing. Initial codes tried to stay conceptually close to the participants' voices and joint understanding often spread over several conversational turns as is common within AAC-mediated conversations $[18,19]$. Focused codes then brought the initial coded data together to build more conceptual ideas and coherence. Nvivo 9.0 (Daresbury, Cheshire, a qualitative software programme) was used to identify the frequency of initial codes and cross-examine across multiple levels. Theoretical coding brought the focused codes together and explored the relationships between them to create explanatory categories. Once the final explanatory categories were established, a core category was sought that determined how the categories related to each other. Memo writing throughout allowed the first researcher to examine emerging theoretical concepts and explore alternative interpretations and identify alternative data collection avenues. Respondent

\footnotetext{
${ }^{2}$ Eye transfer frame (also known as an E-tran frame) is a Perspex sheet with a hole in the centre. Symbols or text are arranged around the outside of the frame. A communication partner holds the frame in front of the individual who uses AAC who will then indicate areas of the frame through eye pointing. The communication partner will follow this lead and verbalise their interpretation which is then agreed with or not. A communication book is commonly used in combination as the individual who uses AAC will indicate on the frame which page of the communication book should be accessed.
}

Hynan, A., Goldbart, J. \& Murray, J. (2015). A grounded theory of Internet and social media use by young people who use augmentative and alternative communication (AAC). Disability and Rehabilitation, early online. DOI 10.3109/09638288.2015.1056387 
validation was sought from four participants of whom three responded to confirm the categories were representative. Feedback was also sought from experienced AAC audiences through conference presentation [68-70] and associated publications [71, 72]. The coding procedure (as described above) led to the identification of nine categories of which 'the desire to use the Internet and social media' was identified as the unifying category by which all the others could be understood (see Table 4). The criteria for judgment of the core were based on the ease with which it related to other categories, the frequency of occurrence within the data and the relevance and flexibility it had within parameters of context, strategies and consequences [64].

Table 4: Identified categories and supporting raw data extracts

\begin{tabular}{|c|c|}
\hline $\begin{array}{l}\text { 1. Desire to use the Internet and online social media } \\
\text { (core category) }\end{array}$ & $\begin{array}{l}\text { Feelings about being online } \\
\text { Peter: "now I'm starting to use it more, very } \\
\text { excited" } \\
\text { Faith: "Excited" } \\
\text { Jack: "happy and excited" } \\
\text { Sean: "fun" } \\
\text { Moira: "it has changed my life better" } \\
\text { Extending use } \\
\text { Olivia: "with Facebook I want to use more" } \\
\text { Caroline (from her blog data) } \\
\text { I have not tried Twitter yet, but maybe I will } \\
\text { try in the future } \\
\text { Researcher: I heard that you would like to use } \\
\text { Skype ... so who would you use Skype to talk } \\
\text { to? } \\
\text { Simon: "my dad and my mum" } \\
\text { If online access was unavailable } \\
\text { Xavier: "I would be very upset ... I'd be lost } \\
\text { without it". }\end{array}$ \\
\hline $\begin{array}{l}\text { Reported use of the Internet and online social } \\
\text { media } \\
\text { A range of internet based activities and types of online } \\
\text { social media sites are used that are typical of young people } \\
\text { with this age demographic. }\end{array}$ & $\begin{array}{l}\text { Caroline (from her blog data): } \\
\text { I use the Internet to look at websites like doctor } \\
\text { who, watch programmes on BBC iPlayer, and } \\
\text { for shopping on Amazon } \\
\text { Nancy: "It's easier for college work" } \\
\text { Nancy: "MSN" } \\
\text { (not consecutive) } \\
\text { Researcher: So has she got a computer in her } \\
\text { room? (referring to Mary's younger sister) } \\
\text { Mary: yeh } \\
\text { Researcher: Yeah, so the two of you might be in } \\
\text { the house, in your rooms and you talk on MSN } \\
\text { Mary: yeah } \\
\text { Keith: "I like Facebook more than Twitter" } \\
\text { Researcher: can you explain why } \\
\text { Moira: "it is different" }\end{array}$ \\
\hline
\end{tabular}

Hynan, A., Goldbart, J. \& Murray, J. (2015). A grounded theory of Internet and social media use by young people who use augmentative and alternative communication (AAC). Disability and Rehabilitation, early online. DOI 10.3109/09638288.2015.1056387 


\begin{tabular}{|c|c|}
\hline & $\begin{array}{l}\text { Researcher: and do you link up on the } \\
\text { PlayStation games with your friends } \\
\text { Ben: 'yes' (nods head) } \\
\text { (not consecutive) } \\
\text { Researcher: which games do you play? } \\
\text { Ben: "MW3, Black ops, FIFA" } \\
\text { Researcher: What things would you use the } \\
\text { Internet to do? } \\
\text { Harriet: F-a-c-e-b-o-o-k, s-h-o-p-p-i-n-g a-n- } \\
\text { d I b-u-i-l-d w-e-b-s-i-t-e-s } \\
\text { Researcher: What kind of websites do you } \\
\text { build? } \\
\text { Harriet: A-n-y-t-h-i-n-g i-t d-e-p-e-n-d-s o- } \\
\text { t-h-e c-u-s-t-o-m-e-r } \\
\text { Researcher: do you earn money from building } \\
\text { websites } \\
\text { Harriet: Yes } \\
\text { Researcher: Is it very important to you to be } \\
\text { able to use the internet and things? } \\
\text { Xavier: yeah, "especially with my (name of } \\
\text { charity) work and everything" } \\
\text { Frequency of use (ranging from once a week } \\
\text { to everyday): } \\
\text { Researcher: you use Facebook with your carer } \\
\text { at home (Olivia goes home at the weekend) } \\
\text { Olivia: yeah } \\
\text { Researcher: do you have a computer at home } \\
\text { Olivia: yeah } \\
\text { Researcher: is it your family's computer or is it } \\
\text { your computer } \\
\text { Olivia: "we share" } \\
\text { Peter: "Now I am able to access it myself I go } \\
\text { on every day" }\end{array}$ \\
\hline $\begin{array}{l}\text { 3. Described support } \\
\text { Participants have been helped to set up and use the Internet } \\
\text { and online social media through educational settings and } \\
\text { home (especially from siblings). Challenges exist for } \\
\text { accessing technical information. Collaboration is a major } \\
\text { part of this category as participants often cannot use the } \\
\text { Internet and social media independently. Collaborating can } \\
\text { be problematic with staff turnover and lacks privacy. }\end{array}$ & $\begin{array}{l}\text { Accessing support for set-up and training } \\
\text { Jack: "InBook" } \\
\text { Researcher: do you use it at home } \\
\text { Jack: 'no' (shakes head) } \\
\text { Researcher: no so do you use it at college } \\
\text { Jack: 'yes' (nods head) } \\
\text { (Georgie uses an E-tran frame) } \\
\text { Researcher: where did you learn to use } \\
\text { Facebook? } \\
\text { SLT: yup this corner, give me a colour } \\
\text { (interpreting eye-gaze) red } \\
\text { Georgie: yeah } \\
\text { SLT: (SLT references colour with } \\
\text { communication book) Georgie's old teacher } \\
\text { Researcher: has anyone ever helped you to do } \\
\text { it? } \\
\text { Keith: "my sister" } \\
\text { Researcher: How did it [using Facebook] start } \\
\text { with your carer? }\end{array}$ \\
\hline
\end{tabular}

Hynan, A., Goldbart, J. \& Murray, J. (2015). A grounded theory of Internet and social media use by young people who use augmentative and alternative communication (AAC). Disability and Rehabilitation, early online. DOI 10.3109/09638288.2015.1056387 


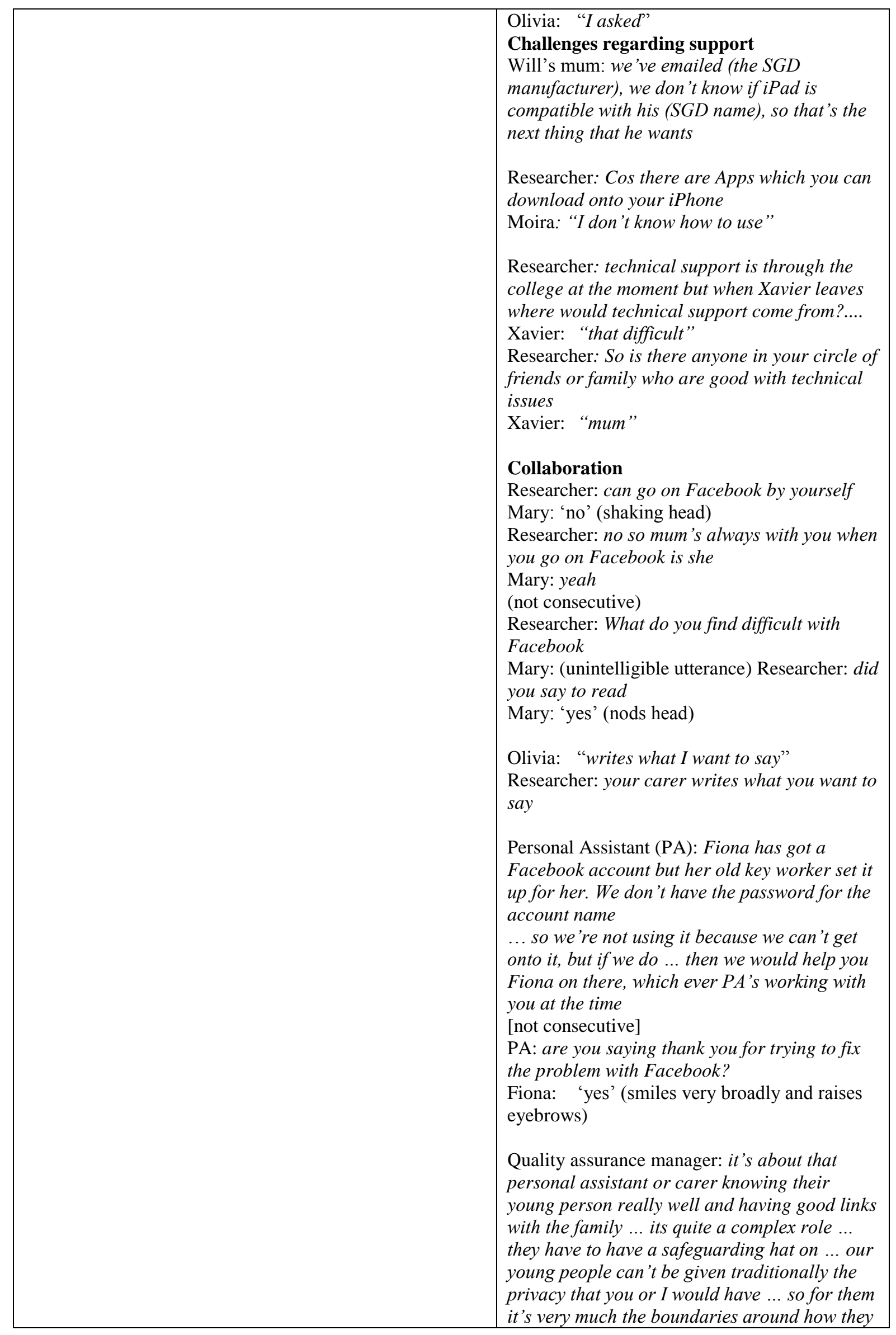

Hynan, A., Goldbart, J. \& Murray, J. (2015). A grounded theory of Internet and social media use by young people who use augmentative and alternative communication (AAC). Disability and Rehabilitation, early online. DOI 10.3109/09638288.2015.1056387 


\section{Online challenges}

Challenges were reported but there was evidence participants coped with issues well. There was an awareness of internet safety and how to use skills for selfprotection. Some participants experienced restrictions of use either due to educational setting policies or parental concerns. Receiving training within an educational setting allowed one young adult to challenge parental restriction.

\section{Access Technology}

Whether or not participants were directly able to access computer equipment or needed intermediate switch technology dictated choice. Those with direct access often chose to use mainstream computers whereas those who relied on switches or a head mouse device would link to mainstream computers through their SGD device. An SGD device can control a remote computer via a cable or manage the situation whilst having as much privacy as possible because they become privy to some very personal bits and pieces that they may well otherwise not be privy to during the day

SLT: Does she not like computers?

Carol: 'yes' (nods head)

SLT: (female name) hates computers so Carol is not only teaching her signing but also about VOCAs and computers.

Caroline (from her blog):

The problem is that's not private, my mum sees everything

Keith: "one of the people wasn't very nice to me, I told them off"

Researcher: Would you put anything on YouTube again (after unwanted contact) Harriet: 'yes' (nods head)

Researcher: so it hasn't frightened you from using YouTube maybe you'd not put such personal stuff on

Harriet: Yeah

Ben: "I blocked him" (referring to someone who had been critical of him online)

Researcher: How did you learn about keeping safe online?

Peter: "Home and school"

Caroline (from her blog data): My parents help me stay safe on-line

Researcher: Do you use Twitter?

Mary: No, I don't want to ... 'cos rude people

\section{Restrictions}

Head of technology 2: we are looking at having an acceptable use policy for students ... bringing their own devices into college making sure that they are using them at the right times.

Erica: "mum say not Facebook and YouTube" (not consecutive)

Researcher: so mum didn't know that you went on YouTube so you did it in secret

Erica: 'yes' (makes huge smile and nods, then laughs)

Methods of access affect participant choice over which types of equipment are used. Keith: "I don't need that one"(referring to integrated SGD) ... "I can use this typewriter" (his name for dedicated SGD without Internet access)

Specialist Teaching Assistant: you can access a computer can't you 


\begin{tabular}{|c|c|}
\hline $\begin{array}{l}\text { Bluetooth connection. A lack of knowledge about what is } \\
\text { available can cause limitations. }\end{array}$ & $\begin{array}{l}\text { Keith: yeah } \\
\text { Nicholas: "special switches eight at } \\
\text { home"'(describing how he accesses a computer) } \\
\text { Nancy: "need my cable to computer" } \\
\text { (connecting SGD to computer) } \\
\text { Researcher: your communication aid is like a } \\
\text { controller and the Bluetooth allows you to go } \\
\text { onto any computer } \\
\text { Will: 'yes' (raises brows) } \\
\text { Lack of required equipment } \\
\text { SLT: Xavier uses a dongle ... which is } \\
\text { something we are getting Olivia sorted out on } \\
\text { Olivia was seen twice but had not received a } \\
\text { USB wireless adapter by the second session. } \\
\text { Olivia: 'I can't ... I can use it when I get set } \\
\text { up" (referring to Facebook) } \\
\text { Challenges with scanning access technology } \\
\text { Researcher: What problems do you have using } \\
\text { the Internet? } \\
\text { Peter: "Access is slow" } \\
\text { Parental knowledge of access equipment } \\
\text { Paul (Peter's father): until somebody tells you } \\
\text { this is the trouble it's the lack of information }\end{array}$ \\
\hline $\begin{array}{l}\text { 6. Speech Generating Device (SGD) Issues } \\
\text { Participants described advantages and disadvantages for } \\
\text { using the Internet and online social media through } \\
\text { integrated SGDs. }\end{array}$ & $\begin{array}{l}\text { Advantages } \\
\text { Researcher: if you were on holiday and didn't } \\
\text { have your PC ... then it's very useful } \\
\text { Moira: 'yes' (nods head vigorously) } \\
\text { Researcher: so you are happy being able to use } \\
\text { the Internet through your communication aid } \\
\text { Xavier: yeah } \\
\text { Researcher's field notes } \\
\text { Xavier typed a text and sent it to one of his } \\
\text { contacts and Fiona demonstrated the creation } \\
\text { of a text using symbolised vocabulary that was } \\
\text { converted to a standard written text by her } \\
\text { SGD. When she received a reply the SGD } \\
\text { turned it into a spoken message for her to listen } \\
\text { to. } \\
\text { Disadvantages } \\
\text { Moira: "I can't play a game" } \\
\text { Will: "It's hard" (to play games) } \\
\text { Power limitations of SGDs } \\
\text { Erica: "not on text" } \\
\text { (not consecutive) } \\
\text { Head of technology 1: do you want me to } \\
\text { explain (Erica confirms) ... The wireless } \\
\text { dongle ... draws so much power that you can } \\
\text { either have the wireless dongle with the } 3 G \text { Sim } \\
\text { card in it or the head mouse but you can't have } \\
\text { both }\end{array}$ \\
\hline
\end{tabular}




\begin{tabular}{|c|c|}
\hline & 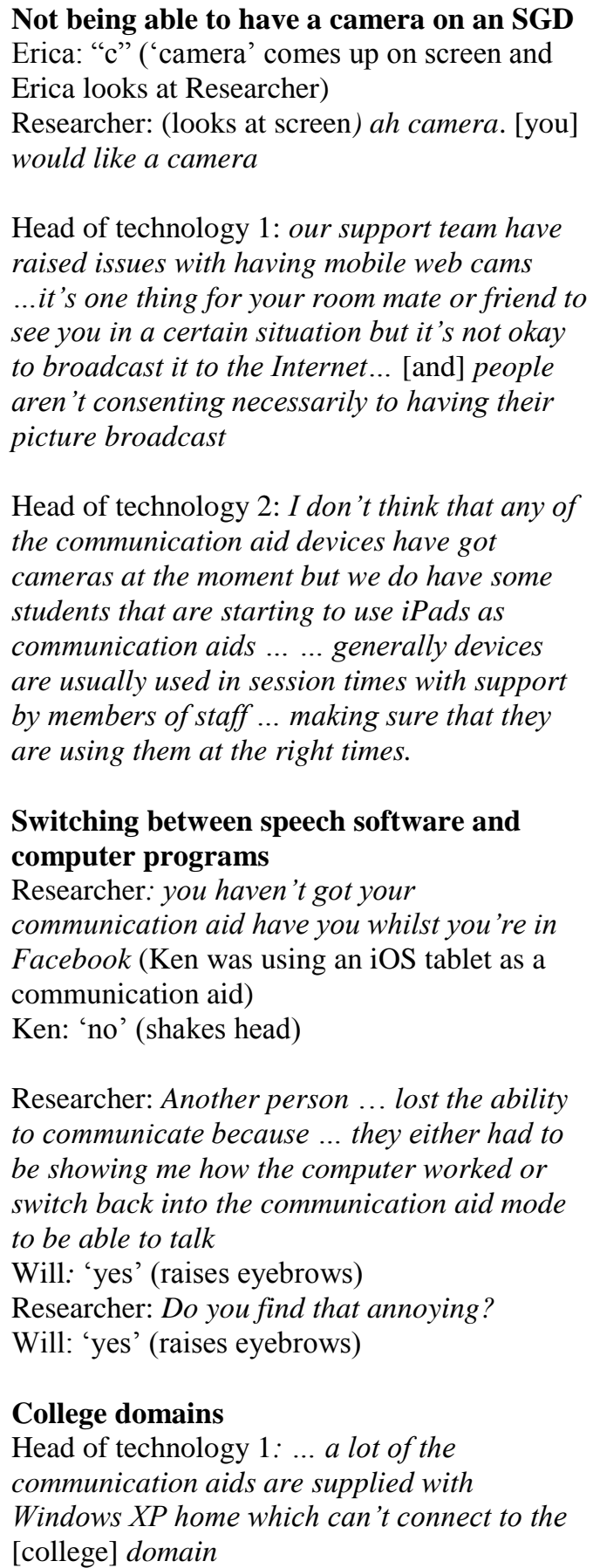 \\
\hline $\begin{array}{l}\text { 7. Self-determination } \\
\text { Perceived control over independent access to information } \\
\text { and self-organisation of activities are interpreted as } \\
\text { improved self-determination in terms of autonomy and } \\
\text { authorship of activities. Another aspect of self- } \\
\text { determination was interpreted as enhanced personal } \\
\text { privacy. }\end{array}$ & $\begin{array}{l}\text { Authorship of activities } \\
\text { Xavier: "I can organise things like meetings } \\
\text { myself" } \\
\text { Peter: "It gave me more independence. I can } \\
\text { organise things like meetings myself"... } \\
\text { "planning trips with my P.A." } \\
\text { Caroline (from her blog data): } \\
\text { Now I can write a message on the (SGD trade } \\
\text { name) then post it on Facebook. I was really, } \\
\text { really excited the first time I did that } \\
\text { independently. }\end{array}$ \\
\hline
\end{tabular}

Hynan, A., Goldbart, J. \& Murray, J. (2015). A grounded theory of Internet and social media use by young people who use augmentative and alternative communication (AAC). Disability and Rehabilitation, early online. DOI 10.3109/09638288.2015.1056387 


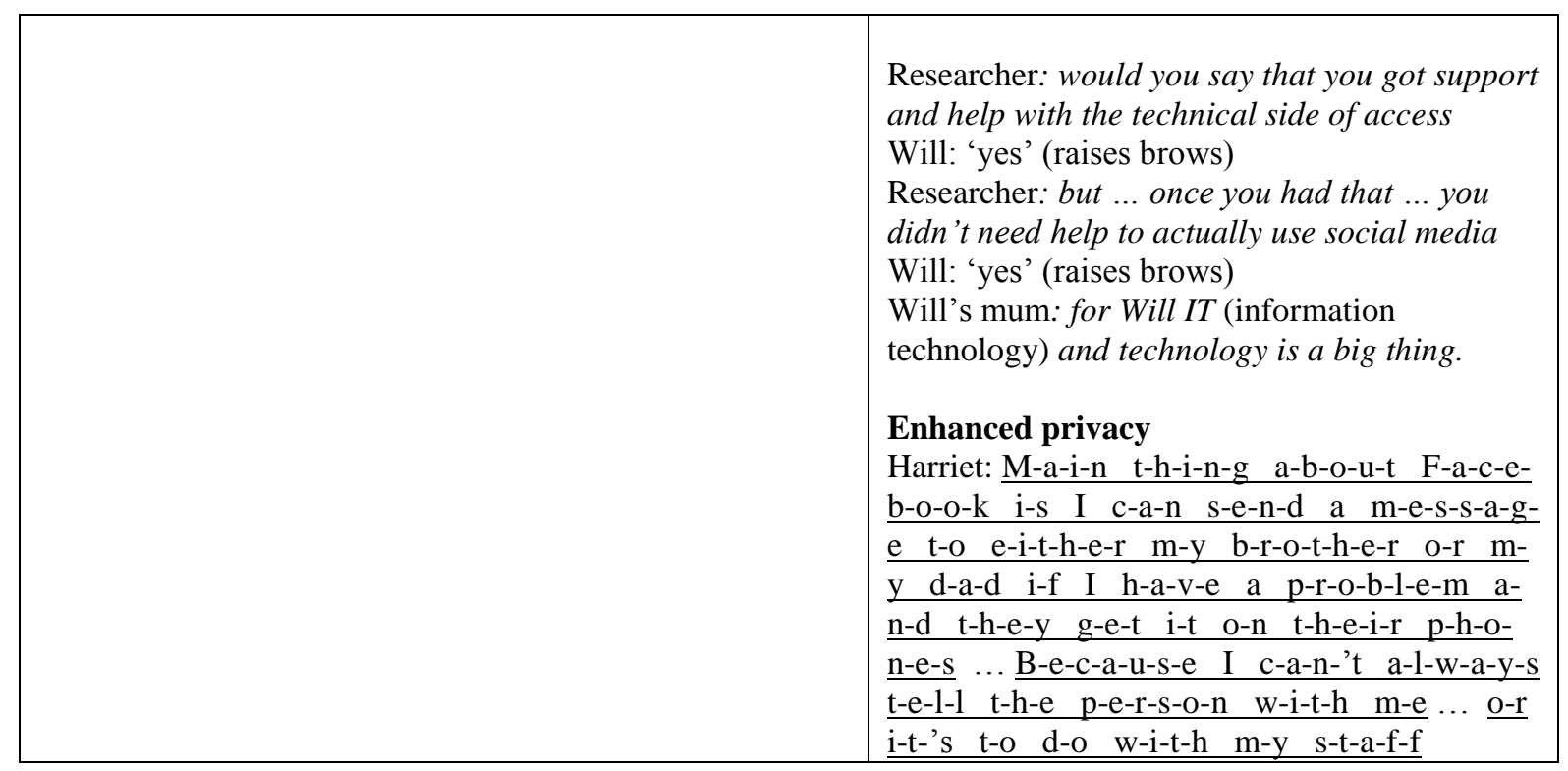




\begin{tabular}{|c|c|}
\hline $\begin{array}{l}\text { 8. Self-Representation } \\
\text { Increased capacity for self-representation online is valued } \\
\text { and seen as a way of extending ways of communicating } \\
\text { with others and also of achieving a sense of equality. }\end{array}$ & $\begin{array}{l}\text { Information about self } \\
\text { Keith: "I like Facebook because I like seeing } \\
\text { me holding Pikachu" } \\
\text { SLT: What is good about Facebook? } \\
\text { Carol: (points to self) } \\
\text { SLT: about you } \\
\text { Researcher: oh because you can give news } \\
\text { about you to your friends } \\
\text { Carol: "yes' (nods head) } \\
\text { Peter: "I have included things I like such as } \\
\text { cricket, Chelsea, theatre, family information, } \\
\text { where I have been" } \\
\text { Nancy: "it good show pictures" } \\
\text { Harriet: I d-o a-d-v-e-r-t-i-s-i-n-g } \\
\text { Researcher: Ah, so you do advertising through } \\
\text { Facebook as part of your business } \\
\text { Harriet: O-n m-y s-t-a-t-u-s } \\
\text { Nancy: "people understand me better in } \\
\text { writing" }\end{array}$ \\
\hline $\begin{array}{l}\text { 9. Online social ties } \\
\text { Young people expressed the main benefit of being online } \\
\text { was to "talk to people". There was evidence of new } \\
\text { friendship opportunities being created and re-establishing } \\
\text { and maintaining old friendships. }\end{array}$ & $\begin{array}{l}\text { Enriching existing social ties - (Bonding) } \\
\text { Ben: "for talk to people" } \\
\text { Xavier: "it me in contact with everybody" } \\
\text { Keith: "I can talk to people on it" } \\
\text { Olivia: "to talk to everyone" } \\
\text { Creating new social ties - (Bridging) } \\
\text { Paul (Peter's father supported Peter to use } \\
\text { Facebook): and then you start getting bits } \\
\text { where people.... are friends of friends as it } \\
\text { were sort of thing } \\
\text { Researcher's field notes } \\
\text { Ben's teaching assistant says he linked up with } \\
\text { her sons on Facebook ... She believes they } \\
\text { would not have had the opportunity to }\end{array}$ \\
\hline
\end{tabular}




\begin{tabular}{|l|l|}
\hline $\begin{array}{l}\text { communicate so well under traditional } \\
\text { circumstances. }\end{array}$ \\
$\begin{array}{l}\text { Keeping in touch long distance - } \\
\text { (Maintained) } \\
\text { Xavier: "yes, } \text { especially when I am here"(at his } \\
\text { residential college) } \\
\text { Olivia: "my old teachers" } \\
\text { Keith: "I send them a text. I find them" (finding } \\
\text { old school friends on Facebook) } \\
\text { Nancy: "can talk dad for in Spain" }\end{array}$ \\
$\begin{array}{l}\text { Reduced isolation } \\
\text { Peter: "It helps independence and can stop } \\
\text { people feeling isolated" (speaking about using } \\
\text { the Internet and Facebook) }\end{array}$ \\
$\begin{array}{l}\text { Dating Opportunities } \\
\text { Researcher: So this means you can keep in } \\
\text { contact with your girlfriend all the time and } \\
\text { read what she has been up to. Is she at this } \\
\text { college? } \\
\text { Jack: "yes' (nods head) } \\
\text { Researcher: Is she in a different group to you } \\
\text { Jack: 'yes' (nods head) }\end{array}$ \\
\hline
\end{tabular}

\section{Results}

The conceptual grounded theory of Internet and social media use by people who use AAC (Figure 2) was developed by seeking to establish how the categories related to the identified core. This was operationalised by exploring: the causal conditions and limitations of the core category, the context within which the core category operates, the interaction and actions that take place to achieve the core category, the types of strategy required and finally the consequences of experiencing the core category.

The first two research aims; to understand access to, and use of, the Internet and social media were addressed within various boxes of the conceptual framework: causal conditions, limitations, interaction/action, context, strategies and consequences. The third and fourth research aims of self-representation and social ties are answered within the consequences box. 
Hynan, A., Goldbart, J. \& Murray, J. (2015). A grounded theory of Internet and social media use by young people who use augmentative and alternative communication (AAC). Disability and Rehabilitation, early online. DOI 10.3109/09638288.2015.1056387 
Figure 2: A conceptual grounded theory of Internet and online social media use by young people who use Augmentative and Alternative Communication (AAC) Licensed under a Creative Commons Attribution-NonCommercial-NoDerivatives 4.0 International License.

Causal conditions

- Access methods that facilitate the use of mainstream computers

- Availability of mainstream technology on integrated SGDs

- Introduction to the Internet and online social media

- Supported to use

- Requesting to use

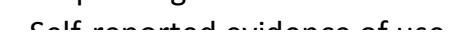

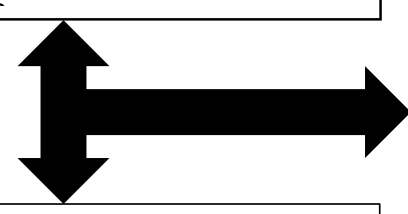

\section{Limitations}

- $\quad$ SGD \& mainstream computer issues

- Toggling (communication/computer)

- Camera unavailability

- Power limitations (eye gaze/3G dongle)

- College domain interface limitations

- Communication device browser limitations

- Computer game limitations

- Technical provision post transition from education

- Limited evidence of using mainstream mobile technologies and Apps

- Limited technical support from personal staff

- Complexities of working collaboratively and lack of privacy when cannot work alone

- Parental technical knowledge and skill limitations

- Restrictions on use of the Internet

- Individual technical knowledge and skills, e.g. orthographic literacy

- Lack of response to requests

- Funding

- Difficulty communicating requirements or problems

\section{Context}

- Where: educational/residential settings and home

- When (frequency):

- If collaborative: when help is available

- If independently: whenever desired (educational setting constraints)

Core Category
Desire to use
the Internet
and online
social media

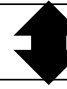

(Who else is involved?) Personal, technical and educational staff family, friends, NHS, AAC manufacturers, AAC charity

- (Why involved?) - to support and respond to desire to use

- (How involved?) - Give advice and training , funding, supply equipment, collaboration

- (Do participants act alone?) If have required hardware, software $\&$ individıal ckills

Strategies (how to bring about)

- Information about \& availability of access technology

- Request technology

- Acquire requested equipment

- Need to either: acquire literacy, have symbolised vocabulary software or collaborate

- Learn how to use equipment

- Have equipment set up by technical staff

- Find suitable collaboration partner

- Rereive trainino

ded theory of Internet and social media use by young people who use augmentative and alternative communication
Consequences (what happens when phenomenon is achieved)

- Self-determination:

- independent access to information, academic materials, own interests

- enhanced privacy

- organising own activities (outings, employment, voluntary charity work) supporting others

- Self-representation

- Increased social capital through:

enriching existing social ties (bonding)

- creating new social ties (bridging)

- maintaining social ties through life changes (maintained)

- "talk to everyone"

- reduced isolation

- Resilience (resources to explore exposure to risk)

(AAC). Disability and Rehabilitation, early on-line. DOI 10.3109/09638288.2015.1056387 
The core category - the desire to use the Internet and social media

All the participants expressed their desire to use the Internet and social media and some said they would feel lost if it became unavailable to them. This desire is also evident within the descriptions of support with one participant indicating gratitude for collaboration. The term collaboration is used within this research to describe the way that participants worked with a communication partner to jointly access, create, share and modify content on the Internet or social media sites; when they were unable to do so independently due to either physical access barriers, cognitive or orthographic literacy limitations.

Having determined the core category as the desire to use the Internet and social media, the three-way arrow within the framework illustrates how the causal conditions and the limitations impact on this core category. A desire to use the Internet has to be fostered by exposure to and opportunities to use of the Internet and social media; yet this exposure and use is simultaneously frustrated if it cannot be enacted to a perceived satisfactory level and resultant limitations are experienced in terms of setting up the internet and social media to the desired level. To clarify this, the causal conditions will be explored followed by the limitations.

\section{Causal conditions for achieving the core category}

The causal conditions within this conceptual grounded theory that set the stage for using the Internet and social media were identified as: access methods and technical innovations that have increased the ability to use mobile technologies and also the integration of mobile technology into SGDs (Table 4, categories 5 and 6). The selfreported engagement with various online activities also fostered the desire to use the Internet and social media (Table 4, Categories 7, 8 and 9).

Another important causal condition was the human support from families, friends and educational settings to engage in online activities and successful requests to use the Internet and social media by young people who use AAC. Many of the participants described finding out about, and being helped to start using, social media either through staff help in educational settings, family, especially siblings, or friends. The digital skills of parents, siblings and friends were a significant influence on use and many participants worked collaboratively with family or personal staff to access, share and input content onto the Internet or social media sites such as Facebook (Table 4, Category 3). 
The issue of requesting to use technology was identified as a causal condition for the desire to use the Internet and social media although it will also be revisited as a limitation later as some requests were unsuccessful. Participants within the current study requested to use social media (Table 4, category 3 ) and also evaluated the strengths and weaknesses of AAC specific and mainstream technology to express their preference between the different options available (Table 4, category 5).

The final causal condition for fuelling the desire to use of the Internet and social media was envisaged as selfreported use within different areas (Table 4, category 2). Participants confirmed they used online technology to access information about fashion, music, sport, theatre, games, academic study, leisure, shopping, television programmes and in some instances pursued opportunities for employment and charity work. The types of social media sites predominantly used were: Facebook, Skype and You Tube; Twitter was not as popular as it was not perceived as being so social. One participant who had been using social media for a while mentioned using MySpace and Bebo. Half of the participants spoke about using texting and email, two had used FaceTime and one used MSN (instant messaging).

\section{Limitations for achieving the core category}

The use of desktop computers and mobile phones was evident whereas the use of mobile technologies was very limited. Only one participant, who did not require switch access, was using an iOS tablet to access the Internet and social media and support his communication. Limitation issues were: switching back and forth between the Internet and software based voice output programmes temporarily halted communication when online on the SGDs and the iOS tablet; cameras being unavailable on SGDs; power limitations of SGDs, for example a USB wireless adapter and an eye gaze system could not be used simultaneously; problems linking into a college domain from particular mainstream operating systems; processing limitations of some SGDs to handle photographs or computer games; switch access difficulties for playing certain types of computer games and ongoing support and technological provision after transition from educational settings (Table 4, category 6). In addition, many of the participants within the current research had older models of SGDs rather than newer more powerful ones. This may also be the reason why some participants said if they had access to desktop computers they preferred to use these for their Internet and social media requirements.

Some participants mentioned their desire to use these mainstream products and the reasons given for not using them were access concerns and a lack of knowledge on how to implement Apps (Table 4, category 3). There 
was an underlying interest in mobile technologies detected within the data, supported by participant descriptions of wanting to have cameras on their SGDs to enable them to access social media sites such as Skype and FaceTime with friends and family and also one report of wanting to access an iOS tablet (Table 4, categories 1 , 3 and 6). Participants wanted cameras on integrated SGDs as it is a popular way of communicating through mobile technologies and also to communicate with their family and friends using mutually understood communication strategies.

Restrictions on use can be seen in the current study regarding regulations within educational settings on when the Internet and social media can be used and a small amount of evidence of parental restrictions (Table 4, category 4). There is also a less concrete form of restriction exercised through the act of collaboration where the co-use of the Internet leads to overt monitoring by parents or staff.

Field notes from observations and discussions with staff within the researched settings showed much of the onus to collaborate on the use social media use falls onto the personal assistants. However, some staff may be uninterested in computers or staff changes can disrupt use (Table 4, category 3).

Having the right information and equipment are vital and some participants did not have the equipment they wanted and parents also lacked the technical knowledge to support them (Table 4, category 3). Technical departments in educational and health settings work hard to support participants and the lead researcher's field notes revealed at times colleges and schools have to rely on outside agencies for equipment supplies or repairs as well as individual funding packages. The reason some students did not appear to have the equipment they wanted may not be down to staff within educational settings. Participants are also likely to face limitations for technical support post transition from education (Table 4, category 3).

Finally, individual skills impacted upon whether the Internet and social media could be accessed as fully as desired, as many websites do not accommodate individual challenges. Some participants identified that social media sites such as Facebook were difficult to read and understand and they required help to understand content (Table 4, category 3).

Interaction and action for achieving the core category

This area of the conceptual grounded theory (Figure 2) explains how the participants enact the desire to use the Internet and social media by describing the interaction/action required to achieve the core category. This area of people who use augmentative and alternative communication (AAC). Disability and Rehabilitation, early online. DOI 10.3109/09638288.2015.1056387 
the grounded theory is where questions are asked of the data in relation to who is involved, why and how are they involved and can a participant act alone to achieve the core category? In terms of who is involved, the data revealed parents, family members, especially siblings, personal staff, teaching and technical staff within educational settings, health professionals, AAC manufacturers and AAC based charities (Table 4, categories 3 and 4). How they are involved is predominantly to provide support by giving advice or training, supplying and repairing equipment or working collaboratively to co-create, share and exchange content information and ideas (Table 4, category 3). There was no universal approach to how collaboration was implemented across the research sites and differing policy guidance had evolved in reaction to individualised incidents. The Quality Assurance Manager within the current study reported personal assistants were asked about their Information Technology (IT) skills at interview, and training could be provided, but it was not a compulsory skill. She also revealed the considerable complexities of the role for personal assistants in terms of balancing respect for privacy, safeguarding and managing familial social links (Table 4, category 3 ).

Approximately two thirds of the participants at the time of the interview had received the relevant hardware for access, had software to enable them to create content and had the individual skills to create, share and exchange content. These participants could act alone although they may have needed help to make cable connections in order to get started and it was apparent they had received help and training in reaching this stage. The other participants ranged from needing support for their orthographic literacy skills but otherwise operated the equipment independently to needing the full support of a communication partner to operate equipment and create, share and exchange content. As Skype does not require text input some participants once they had received help to log on could communicate with family and friends using their individual communication strategies.

\section{Context for achieving the core category}

This part of the grounded theory addresses the issue of context in relation to the core category. In terms of 'where', participants were engaging with the Internet and social media within their educational settings but also at home with family, friends and/or personal care staff. In terms of considering 'when', this was dependent on whether use was collaborative or independent as it could affect frequency. Some participants reported having to wait to go home at weekends to work with personal staff and parents using shared resources within the home. 
For those able to work independently, they were technically free to use the Internet and social media when desired within the limitations of educational setting restraints and parental limitations.

\section{Strategies for achieving the core category}

This part of the grounded theory refers to the strategies that participants have to engage with once they have acted or interacted to bring about the desired use of the Internet and social media. The focus is on what factors the young people have to either initiate proactively or respond to in order to experience using the Internet and social media independently or collaboratively. Acquiring the right equipment allowed many participants to access the Internet and social media for the first time independently as demonstrated by the availability of symbolised vocabulary on an integrated SGD that allowed independent texting (Table 4, category 7). Being orthographically literate made an enormous difference to the level of independence that participants could experience (illustrated throughout all of the categories in Table 4). Other vital strategies are learning how to use access technology, having equipment set up and receiving training (Table 4, categories 3 and 5).

\section{Consequences for achieving the core category}

This area of the conceptual grounded theory (Figure 2) illustrated the consequences when the core category is enacted leading to perceived benefits in areas such as self-determination, self-representation, social capital (bonding, maintaining and bridging social ties), reduced isolation, building resilience and possible dating opportunities.

A sense of self-determination was reported by participants in relation to self-authorship of activities and also feeling that social media offered enhanced privacy in personal relationships (Table 4, category 7 ). The necessity to have high levels of personal care, coupled with communication limitations, means it can be very difficult for people who use AAC to organise personal activities and conduct private conversations with family and friends.

Evidence arose from the data to show that the participants enjoyed an increased sense of self-representation through using social media sites, especially Facebook. They identified opportunities to show humour, create personal narratives through representing significant aspects of their lives and using the Facebook timeline for creating an historical framework (Table 4, category 8).

The conceptual grounded theory also shows how social capital was increased for the participants (Table 4, category 9). This was achieved through enriching existing relationships (bonding social capital) with family and 
friends especially over distance, opportunities to make contact and socially network with people who are 'friends of friends' (bridging social capital) and also to retaining relationships with people from previous life experiences (maintained social capital). Participants also identified feeling a sense of equality in how they could express themselves, voice opinions and follow interests in the same way as other people who used social media. Some also said they felt other people could understand them better in writing. One of the main descriptions applied to the benefits of the Internet and social media by the participants was the opportunity to talk to 
everyone. The improved opportunities for talking to people and keeping in touch with family reduced feelings of isolation (Table 4, category 9).

Having the opportunity to use the Internet has provided the young people within this study with an important resource to exercise resilience and manage risk (Table 4, category 4). The research revealed a small amount of support that social media was providing one participant with an opportunity to keep in contact with his girlfriend as their paths rarely crossed within their college environment. For people who use AAC being able to talk online may have significant ramifications for intimate relationships (Table 4, category 9).

\section{Discussion}

This section will discuss the most pertinent issues raised within the conceptual grounded theory framework within the context of existing knowledge. The structure follows the same headings as the results.

\section{Core Category - the desire to use the Internet and social media}

Having a desire to use the Internet and social media supports broad research within contemporary Western societies that young people within the participants' age demographic are interested in being online as it has become thoroughly embedded within their lives [38]. Sociological theories report adolescence is a time when bonds to parents weaken and peer relationships become more significant [37]. Many adolescents claim they could not live without the Internet and love how new technology helps them communicate with people [73], which is supported by Helseth and Misvaer [74] who found peer relationships were a psychosocial factor that adolescents used to evaluate their quality of life. Within the current study, the desire to use the Internet and social media (especially Facebook) was unanimously expressed amongst the participants and extends understanding from previously cited literature that people who use AAC perceive benefits for widening and clarifying communication with others through the use of mobile technologies [7-14].

\section{Causal conditions for achieving the core category}

Each participant had a unique profile in terms of individual motor skills, cognitive ability and language/orthographic literacy skills that had a bearing on how they engaged with technology. Ellcessor [75] critically discussed the development of the Internet and social media through the lens of disability and stated that unique access methods can lead to innovation in terms of how content is produced, consumed and shared. The current study showed that six participants with direct access and orthographic literacy skills preferred to use 
mainstream devices for their Internet and social media requirements; although four of them also owned integrated SGDs these were not the preferred devices for going online. Seven participants used mainstream computers either via switches that controlled mouse movements, a switch accessible onscreen keyboard or had their SGDs set up to drive independent computers. Chapple [76] explained SGDs can link up to independent computers either through a cable into the USB port or wirelessly through Bluetooth technology allowing the SGD to act like a remote control. Four participants with limited mobility who relied on indirect access reported only going online through their SGDs. When totally integrated SGDs started to make their mark within the AAC industry, Chapple identified it had particular significance for individuals with severe mobility challenges. The current study supports this assumption with reported examples of first time opportunities to use the Internet and social media through integrated SGDs by utilising individualised language programmes and personalised access methods (Table 4, category 6 and 7).

As shown earlier, Raghavendra et al. [9] found the digital skills of parents, siblings and friends were significant influences on levels of computer use. Participants also spoke about working collaboratively with family or personal staff to access, share and input content onto the Internet or social media sites such as Facebook. Little research exists within the field of AAC to discuss this finding but Naslund and Gardelli [77] illustrated how working collaboratively with experienced partners to use computers is often a vital component of supporting agency for people with learning disabilities. Within this study, a number of participants reported their initial engagement with social media was facilitated through collaboration and led to an exploration of whether they could extend their use to other contexts or become independent through hardware and/or software modifications. Support was identified from NHS agencies, AAC manufacturers and educational settings. Two training tools were identified: an e-portfolio called InFolio (http://www.jisctechdis.ac.uk/techdis/learnersandstudents/infolio) and a secure social networking tool called InBook (http://inbook.jisctechdis.ac.uk/). These training resources were designed to teach young people with disabilities, particularly those with learning disabilities, how to use social media safely before moving onto mainstream unprotected sites.

The concepts of digital agility (being familiar with technology, having a range of strategies and confidence in self ability) and digital decision making (making decisions regarding technology use) were highlighted by Seale, Draffan and Wald [78] as being vital to recognise for people with disabilities in order to encourage perceptions of empowerment. Moving away from a deficit and barriers perspective to recognising how people with disabilities can dictate their own terms and exercise agency over their use of digital tools is important. 
Participants within the current study demonstrated digital agility and digital decision making through their requests to use the Internet and social media and also through their evaluation of the strengths and weaknesses of AAC specific and mainstream technology. Within the current study, the participants use of a range of social media sites supports previous literature that illustrates how opportunities for online entertainment and social communication are known to be strong motivators for young people to digitally engage [30, 37].

\section{Limitations for achieving the core category}

Gathering limitation information from specific groups is argued by Newell [79] as necessary to prevent certain users being prioritised over others and illustrate the pitfalls of universal design solutions. An area of frustration for the participants within this research was limited choice and challenges to play certain types of computer games due to the childish content of easy to control games and intricate controls for games that had more adolescent/adult content. A systematic review by Chantry and Dunsford [80] into computer use by children with severe and complex disabilities showed finding ways for assistive and adaptive technology to offer access to existing games can open up opportunities for engagement and participation with families and peers.

As discussed earlier, the emergence of mainstream mobile technologies and Apps has produced an enormous shift of focus within the AAC field and increased opportunities for the use of mainstream digital technology by people who use AAC. Despite the huge potential and impact of this paradigm shift in the world of AAC, within the current study mobile technologies were not a major influence on the use of the Internet and social media. The low level of reported use within the current study supports literature that access problems to mainstream devices are major barriers to people with physical disabilities [81]. Knowing how to establish access can be difficult, for example switch access was established with Apple products through the launch of iOS7 software in 2013 but it takes time for information to become widespread. A review of access interface strategies by Fager et al. [82] concluded that access is still the main barrier preventing the use of mobile technologies for individuals with severe mobility challenges. The lack of alternative access for AAC users within the mainstream device market is described by Chapple (76) as a return to the Stone Age. The development of a digital divide amongst young people who can and cannot access digital resources threatens social inclusion as most young people expect their peers to be online and social media use is integral to their relationships [30]. Young people who are unable to engage with online activity are suggested by Soderstrom [40] to be at risk of being marginalised and excluded from their peer communities. 
The current study revealed some participants had individual difficulties in areas such as understanding and navigating sites such as Facebook. The internationally definitive standard for web site accessibility, Web Content Accessibility Guidelines (WCAG) 2.0, was discovered by Hollier [83] not to be implemented fully by many social media sites such as Facebook and Twitter. This issue alongside limitations for orthographic literacy meant many participants worked collaboratively with personal staff. The technical knowledge and complexity of engagement for personal staff to input and share content on social media sites were: training in technical equipment, professional boundaries between home and educational environments, entering into potentially private relationships with families and friends and knowing how to handle, report and negotiate disclosure of potentially negative content. Collaborative social media use may become more of an issue for the personal care workforce in the future. Demographic information collected through survey data by Hall and Wreford [84] from care workers within the UK, found $71 \%$ were female, $24 \%$ were under $35,51 \%$ were aged between 35 and 54 , $25 \%$ were aged 55 or over and $60 \%$ were in the lower socioeconomic grades of C2, D and E. This has implications in terms of workforce development as digital literacy skills are known to be negatively affected by age and low socioeconomic status [85]. Within the current study, siblings were mentioned more frequently than parents as supporting social media use and some parents evidently found it difficult to find out about technology. This reinforces Raghavendra et al.'s [9] findings that there is great variability between families and friends in terms of technical knowledge and digital literacy abilities.

\section{Interaction and action for achieving the core category}

Raghavendra et al. [9] found participants with physical disabilities had emphasised that their siblings and friends were heavily involved in teaching them digital skills and had showed them how to use the Internet and helped them to use certain sites and also connected with them online. Within the context of the current study, it was evident that working collaboratively to use mainstream technology with an orthographically literate adult on motivational activities (such as Facebook) had enhanced the opportunity for orthographic exposure.

Despite difficulties acquiring orthographic literacy outlined earlier, Smith [86] stated it is possible for people who use AAC to acquire this skill especially if consideration is given to increasing exposure to literature within motivational environments. There may be implications from the collaborative use of social media that impacts on the emerging orthographic literacy skills of people who use AAC. Sitting beside a literate companion and 
having the opportunity to co-create content, watch that content being constructed, observe the written responses and hear them being read may prove to be supportive.

\section{Context for achieving the core category}

Within the current study, participants who worked collaboratively would have to wait until help was available, in some cases this was only at the weekend when they went home and worked with personal staff or parents sharing computers. This supports the findings of Raghavendra et al. [9] who reported competing uses at home could create a barrier as children and parents often vied for access, especially when families only had one shared computer.

\section{Strategies for achieving the core category}

A clear picture emerged within this research that orthographic literacy skills were an important strategy for independent use of the Internet and social media as many physical limitations could be overcome with appropriate access technology. Although AAC manufacturers' newly developed software packages have had an enormous impact on allowing participants without orthographic literacy to use social media for the first time, it was clear that a lack of orthographic literacy skills had the biggest impact for preventing sophisticated and broad Internet and social media engagement. Orthographic literacy was argued by Raghavendra et al. [87] to be a bigger barrier than primary disability or technical limitations for people who use AAC to engage with the Internet and social media. Non-disabled children get intensive orthographic literacy training in schools which was not the approach that Horton [88] experienced within his special educational setting. Kelford-Smith, cited by Beukelman \& Mirenda [89] found self-help and communication skills can often take priority over orthographic literacy training for children who use AAC.

\section{Consequences}

Self-determination was identified by Milner and Kelly [90] as one of five fundamental antecedents for creating a sense of community participation by people with disabilities due to being able to use their own skills to achieve autonomy in self-chosen activities. They identified a vital aspect for an experience to feel qualitatively different is the degree of authorship felt. Although their research concentrates on inclusion within a physical community, the conceptual basis they outlined is suitable for understanding some of the perceived online benefits revealed for self-determination within this study. This was reiterated by Smith and Murray [91] who suggested measuring 
the impact for self-efficacy and self-determination is valuable when evaluating interventions using high-tech AAC technology. In the current study, participants perceived control over independent access to: information for academic materials, following own interests, self-organisation of activities, following employment and charitable work opportunities and supporting others. This has been interpreted and expressed within the conceptual grounded theory as indication of a perceived increase for self-determination due to the Internet and social media supporting autonomy and authorship of these activities. The development of SGDs that can interconnect with the Internet is a positive advantage for enhancing employment opportunities and Duckett [92] suggests part-time positions, taking more control over running personal care teams, voluntary work, mentoring younger people who use AAC or working as motivational speakers or disability advocates are all areas for consideration.

The ability to support others evidenced in the data, when one parent recognised the technical skill of her son and another participant was reported as training her personal assistant, supports the findings of Raghavendra et al. [9] who reported parents of children with physical disabilities were beginning to take steps to learn more about the Internet's potential and sometimes found support from younger family members and their children with disabilities. This is a phenomenon noted on a broader scale within mainstream society; Mesch and Talmud [37] discussed how the balance of power is changing in many families as adolescents become the technical experts within the household. The opportunity revealed for enhanced privacy through independent access to the Internet and social media supports existing literature; McNaughton and Bryen [47] identified people who use AAC often feel frustrated by a lack of privacy.

The current study found participants reported being able to express themselves more fully with people when they used online communication and experienced greater opportunities to express humour, create narratives and feel a sense of equality with others. Identity issues on Facebook were investigated by Zhao et al. [93] who suggested their participants enjoyed putting things they were proud of on Facebook and the promotion of an ideal self-image had concrete consequences within the offline world. One of the online benefits for people with disabilities was argued by Bowker and Tuffin [94] to be enhanced choice over self-representation, which was also supported by Clarke et al. [95] who found AAC technology supported participant perceptions of being able to say what they liked and tell jokes. One of the challenges faced by young adolescents who use AAC was identified by Tavares and Peixoto [96] to be limited access to a variety of conversational partners and stated conversational skill development depended on the communication experiences available. 
Increased social capital opportunities may have important ramifications for people who use AAC as social interaction can be challenging for people who use AAC within face-to-face interactions. Many studies have shown reduced social participation opportunities for people with cerebral palsy [41-46]. Targeted intervention to support adolescents with physical disabilities to use the Internet and social media was shown by Raghavendra et al. [9] to increase the number of online communication partners and offer new ways to extend social connections and Ellison et al. [35] also found social media supported the maintenance of social ties. Within the current research, participants described how they used social media, especially Facebook, to contact friends and teachers from old schools and to keep in touch with friends who had moved onto college. They also described keeping in touch with family and friends in different countries and searching for people they had lost touch with online. SGDs may have the names of old friends and teachers no longer seen programmed within the vocabulary items and social media is changing the dynamics of enriching and maintaining social ties for young people who use AAC. The current finding that isolation may be reduced though social media supports previous literature by Ballin and Balandin [97] who found increased levels of loneliness in adults with cerebral palsy is in part due to difficulties accessing communication technologies such as telephones and Internet sites. Loneliness was shown by Cooper et al. [98] to be a risk factor for people who use AAC that can be psychologically demoralising but communication with others, especially through online resources helped ease feelings of loneliness. On the other hand, Raghavendra et al. [7] found no significant changes in measures of loneliness in their intervention-based research to support Internet and social media use with young people who use AAC; although they suggested perceptions may take time to emerge.

Exposure to risk is an important facet of developing coping strategies and the current study showed some participants had experienced challenging situations online. Runswick-Cole and Goodley [99] explored concepts of resilience from a critical disability studies perspective and proposed a 'networks of resilience model' that created interconnections between resources. The current participants reported being assertive in relation to unkind online comments, blocking people from sharing material online, reacting to an invasion of privacy by severing a social relationship, using Facebook to discuss issues privately with staff, and accessing social media despite parental wishes. By asking for equipment to extend their use of social media (e.g. USB wireless adapters or cameras), or requesting to use equipment either collaboratively or via access technology, they have demonstrated their awareness of the resources they wish to access and considered in what ways, and from whom, assistance could be sought. The social media teaching tools being used within the educational settings 
provide resources to cope within publicly open forms of social media. Exposure to online risk was suggested by Livingstone et al. [38] to be beneficial for adolescent development if not outside an individual's ability to cope.

People with physical disabilities have few opportunities to be alone as they tend to have personal assistants in attendance. This is likely to have a major impact on the ability of adolescents who use AAC to spend private time together, so having an online connection may be highly significant. The finding within the current study that being online facilitated a romantic relationship supports Whitty [100] who argued the Internet is opening up a unique environment for people to learn about and experience relationships and sexuality, especially adolescents who can escape pressures such as school, parents and homework and have fun online and explore self-identity.

The cumulative effect of the consequences suggests there are various important issues that underline why the desire to use the Internet and social media is so clearly expressed by the participants. To understand these factors it can be useful to consider the work of Milner and Kelly [90] who identified five fundamental antecedents for community participation and inclusion by people with disabilities. These are: self-determination (autonomy to choose own activities), social identity (built over time through ongoing interpersonal contact), reciprocity and valued contribution (being valued and perceived as contributing helps challenge perceptions of dependence), participatory expectations (empowered through others and being able to challenge assumptions), and psychological safety (feeling valued as a member of a community). Mahar, Cobigo \& Stuart [101] also identified five antecedents (subjectivity, reciprocity, groundedness, dynamism and self-determination) for a sense of social belonging within their narrative literature review of community-based programmes for people with disabilities. Although using different terminology these map closely to the research of Milner and Kelly [90]. The current authors suggest that these antecedents can be mapped into the grounded theory of Internet and social media use by young people who use AAC through the consequences area of the framework (Figure 2). Self-determination is reflected in the ability to self-author activities; social identity is described though improved opportunities for self-representation; reciprocity is evidenced through perceptions of maintained close social ties with families and friends; participatory expectations can be seen through participant descriptions of feeling able to "talk to everyone" and reports of challenging others' perceptions. Psychological safety can in part be satisfied through reports of reduced feelings of isolation through engagement in social media and having opinions valued by others. 


\section{Limitations of the current study}

Challenges gaining respondent validation of the lead researcher's results through email limit the confidence that can be placed in the results. The lack of actual Internet or social media data to confirm observations may also be a limitation of the conceptualised grounded theory framework. Despite attempts to recruit within a wide age range (14-24 years), only one 14 year old participant fell outside of an actual age range of 17-23 years and his views were not qualitatively different from those of the older participants.

\section{Conclusion}

The core category that emerged from the grounded theory is that young people who use AAC have a clear desire to use the Internet and social media but face challenges, especially regarding accessibility and limited orthographic literacy skills. The benefits of being online were perceived by the participants as: increased opportunities for self-determination and self-representation; increased online social capital opportunities; talking to everyone; reduced isolation; possible dating support and tools with which to build resilience networks [102, 103]. These findings may have implications for future research to consider whether being online can support perceptions of social inclusion and participation for people who use AAC, in much the same way as previously discussed antecedents support perceptions of community-based social inclusion and social belonging in the offline world.

Collaborative practice to use the Internet and social media may have important implications for developing orthographic literacy skills through motivation and exposure. There are also ramifications for workforce development as the role of personal assistants is clearly changing in light of the desire of people who use AAC to engage in online environments. Future research may wish to explore these issues and consider using alternative research methodologies such as data collection through Internet-based platforms and quantitative methods.

\section{Acknowledgements}

The authors acknowledge the contribution of Dr Geoff Bunn for providing consultation during the conceptualisation of this grounded theory. 


\section{Declaration of Interest}

The authors report no conflict of interest. The authors alone are responsible for the content and writing of the paper. The research was supported by a PhD studentship bursary from Manchester Metropolitan University and by grants from Communication Matters UK and The Royal College of Speech and Language Therapists, UK.

\section{References}

1. Higginbotham DJ, Shane H, Russell S, Caves K. Access to AAC: past, present and future. Augment Altern Commun 2007;23:243-57

2. Lathouwers K, de Moor J, Didden R. Access to and use of Internet by adolescents who have a physical disability: A comparative study. Res Dev Disabil 2009;30:702-11

3. Morris J. Including all children: finding out about the experiences of children with communication and/or cognitive impairments. Child Soc 2003;17:337-48

4. Rabiee P, Sloper P, Beresford B. Doing research with children and young people who do not use speech for communication. Child Soc 2005;19:385-96

5. Wickenden M. 'Talking to teenagers: using anthropological methods to explore identity and lifeworlds of young people who use AAC'. Comm Dis Quart 2009;32:151-63

6. Boggis, A. Deafening silences: Researching with inarticulate children. Disabil Stud Quart 2011;31:13-13. http://dsq-sds.org/article/view/1710. Accessed 2013 Aug 20

7. Grace E, Raghavendra P, Newman L, Wood D, Connell T. Learning to use the Internet and online social media: What is the effectiveness of home-based intervention with youth with complex communication needs? Child Lang Teach Ther 2014;30:141-57

8. Raghavendra P. Wood, D, Newman L, Lawry J. “Why aren't you on Facebook?”: Patterns and experiences of using the Internet among young people with physical disabilities. Technol Disabil 2012; 24:149-62

9. Raghavendra P, Newman L, Grace E, Woods D. 'I could never do that before': Effectiveness of a tailored Internet support intervention to increase the social participation of youth with disabilities. Child Care Health Dev 2013;39:552-61 
10. Garcia TP, Loureiro JP, Gonzalez BG, Riveiro LN, Sierra AP. The use of computers and augmentative and alternative communication devices by children and young with cerebral palsy. Assist Technol: The official journal of RESNA 2011; 23:135-49

11. Cohen K, Light J. Use of electronic communication to develop mentor-protégé relationships between adolescent and adult AAC users: Pilot study. Augment Altern Commun 2000;16:227-38

12. Dattilo J, Estrella G, Estrella LJ, Light J, McNaughton D, Seabury M. "I have chosen to live life abundantly": Perceptions of leisure by adults who use augmentative and alternative communication. Augment Altern Commun 2008;24:16-28

13. Rackensperger T, Krezman C, McNaughton D, Williams MB D'Silva K. "When I first got it, I wanted to throw it off of a cliff': The challenges and benefits of learning AAC technologies described by adults who use AAC. Augment Altern Commun 2005; 21:165-86

14. Atanasoff LM, McNaughton D, Wolf PS, Light J. Communication demands of university settings for students who use augmentative and alternative communication (AAC). J Postsec Educ Disabil, 1998;13:3147. https://www.ahead.org/publications/jped/vol_13. Accessed 2013 Mar 23

15. Livingstone $\mathrm{S}$. Taking risky opportunities in youthful content creation: teenager's use of social networking sites for intimacy, privacy and self-expression. New Media Soc 2008;10:393-411

16. Waller A, O’Mara DA. Aided communication and the development of personal story telling. In von Tetzchner S, Grove N, editors. Augmentative and alternative communication: Developmental issues. London:Whurr Publishers; 2003. p 256-71

17. Todman J, Alm N, Higginbotham J, File P. Whole utterance approaches in AAC. Augment Altern Commun 2008;24:235-54

18. Clarke M, Wilkinson R. Interaction between children with cerebral palsy and their peers 2: Understanding initiated SGD-mediated turns. Augment Altern Commun, 2008:24:3-15

19. Clarke M, Wilkinson R. Interaction between children with cerebral palsy and their peers 2: Understanding initiated VOCA-mediated turns. Augment Alternative Commun 2008;24:3-15

20. Bloch S. Anticipatory other-completion of augmentative and alternative communication talk: a conversation analysis study. Disabil Rehabil 2011;33:261-69

21. Grove N, Tucker S. Narratives in manual sign by children with intellectual impairments. In: von Tetzchner S, Grove N, editors. Augmentative and alternative communication: Developmental issues. London: Whurr Publishers; 2003. p 229-55 
22. Waller A. Communication access to conversational narrative. Top Lang Disord 2006;26:221-239

23. Stevens S. Have you seen my new mobile phone? Merging AAC with mobile telephony. Commun Matt $2011 ; 25: 5-7$

24. Hyatt GW. The iPad: a cool communicator on the go. Perspect Augment Altern Commun 2011;20:24-7

25. Smith MM. Reading abilities of nonspeaking students: Two case studies. Augment Altern Commun 1992; $8: 57-66$

26. Browning N. Literacy of children with physical disabilities: A literature review. Can J Occup Ther 2002;69:176-82

27. Sturm J, Clendon S. Augmentative and alternative communication, language and literacy: Fostering the relationship. Top Lang Disord 2004;24:76-91

28. Sundqvist A, Ronnberg J. A qualitative analysis of email interactions of children who use augmentative and alternative communication. Augment Altern Commun 2010;26:255-66

29. Vallor S. Flourishing on Facebook: Virtue friendship and new social media. Ethics Inform Technol, 2011;14:185-99

30. Livingstone S, Helsper E. Gradations in digital inclusion: children, young people and the digital divide. New Media Soc 2007;9:671-96

31. Holt L. Embodied social capital and geographical perspectives: performing the habitus. Prog Hum Geogr 2008;32:227-46

32. Holt L. Young peoples' embodied social capital and performing disability. Child Geogr 2010; 8:25-37

33. Valenzuela S, Park N, Kee KF. Is there social capital in a social network site?: Facebook use and college students' life satisfaction, trust, and participation. J Comp-Mediat Commun 2009;14:875-901

34. Williams D. On and off the "net: Scales for social capital in an online era. Journal of computer-mediated communication 2006;11:593-628. http://jcmc.indiana.edu/vol11/issue2/williams.html. Accessed 2013 Aug 13

35. Ellison NB, Steinfield C, Lampe C. The benefits of Facebook “friends:" Social capital and college students' use of the online network sites. J Comp-Mediat Commun 2007;12:1143-68

36. McMillan SJ, Morrison M. Coming of age with the Internet. New Media Soc, 2006; 8:73-95

37. Mesch G, Talmud I. Wired Youth: The social world of adolescence in the information age. London: Routledge; 2010 
38. Livingstone S, Haddon L, Gorzig A, Olafsson K. Final report, EU kids online II. The London school of economics and political science.

http://www.1se.ac.uk/media@1se/research/EUKidsOnline/EU\%20Kids\%20II\%20(2009-

11)/EUKidsOnlineIIReports/Final\%20report.pdf. 2011. Accessed 2012 July 12

39. Watson N. Well, I know this is going to sound very strange to you, but I don't see myself as a disabled person: Identity and disability. Disabil Soc 2002;17:509-27

40. Soderstrom S. Offline social ties and online use of computers: A study of disabled youth and their use of ICT advances. New Media Soc 2009;11:709-27

41. Imms C. 'Children with cerebral palsy participate: A review of the literature'. Disabil Rehabil 2008;30:1867-84

42. Fauconnier J, Dickinson HO, Beckung E, Marcelli M, McManus V, Michelsen S, Parkes J, Parkinson KN, Thyen U, Arnaud C, Colver A. Participation in life situations of 8-12 year old children with cerebral palsy: cross sectional European study. BMJ 2009;338:1116-1121

43. Raghavendra P, Olsson C, Sampson J, McInerney R, Connell T. School participation and social networks of children with complex communication needs, physical disabilities, and typically developing peers. Augment Altern Commun 2012;28:33-43

44. Kang LJ, Palisano RJ, Orlin MN, Chiarello LA, King GA, Polansky M. Determinants of social participation - with friends and others who are not family members - for youths with cerebral palsy. Phys Ther, 2010;90:1743-1757

45. Kang LJ, Palisano RJ, King GA, Chiarello LA. A multidimensional model of optimal participation of children with physical disabilities. Disabil Rehabil 2014;36:1735-41

46. Batorowicz B, Campbell F, von Tetzchner S, King G, Missiuna C. Social participation of school-aged children who use communication aids: The views of children and parents. Augment Altern Commun, $2014 ; 30: 237-51$

47. McNaughton D, Bryen DN. AAC technologies to enhance participation and access to meaningful societal roles for adolescents and adults with developmental disabilities who require AAC. Augment Altern Commun 2007;23:217-29

48. Smith MM. The dual challenges of aided communication and adolescence. Augment Altern Commun 2005; 21:67-79 
49. Light J, McNaughton D, Krezman C, Williams M, Gulens M, Galskoy A, Umpleby M. The AAC Mentor Project: Web-based instruction in sociorelational skills and collaborative problem solving for adults who use augmentative and alternative communication. Augment Altern Commun 2007;23:56-75

50. Barnfather A, Stewart M, Magill-Evans J, Ray L, Letourneau N. Computer-mediated support for adolescents with Cerebral Palsy or Spina Bifida. Comput Inform Nurs 2011;29:24-33

51. Seymour W, Lupton D. Holding the line online: Exploring wired relationships for people with disabilities. Disabil Soc, 2004;19:291-305

52. Kirk S. Transitions in the lives of young people with complex healthcare needs. Child Care Health Dev 2008;34:567-75

53. AAC-RERC. Mobile devices and communication Apps: An AAC-RERC white paper. Baltimore, MD; 2011. http://aac-rerc.psu.edu/index.php/pages/show/id/46. Accessed 2013 Jul 29

54. Rummel-Hudson R. A revolution at their fingertips. Perspect Augmentative Alternative Commun $2011 ; 20: 19-23$

55. Shane H C, Blackstone S, Vanderheiden G, Williams M, DeRuyter F. Using AAC technology to access the world. Assist Technol: The official journal of RESNA, 2012;24:3-13

56. Higginbotham J, Jacobs S. The future of the Android operating system for augmentative and alternative communication. Perspect Augmentative Alternative Commun 2011; 20:52-56

57. DeRuyter F, McNaughton D, Caves K, Bryen DN, Williams M. Enhancing AAC connections with the world. Augment Altern Commun, 2007;23:258-70

58. Raghavendra P, Bornman J, Granlund M, Bjorck-Akesson, E. The world health organization's international classification of functioning, disability and health: Implications for clinical and research practice in the field of augmentative and alternative communication. Augment Altern Commun 2007;23:349-61

59. Lidstrom H. ICT and participation in school and outside school activities for children and youths with physical disabilities. [dissertation] Sweden:Karolinska Institutet; 2011.

60. AAC-RERC. The 2012 state of the science conference in AAC: AAC-RERC final report. Baltimore, MD:AAC-RERC 2012 Jun 28. http://aac-rerc.psu.edu/documents/2012_SOSC_in_AAC_Final_Report.pdf. Accessed 2013 Aug 12

61. Bryman, A. Social Research Methods. Oxford: Oxford University Press 2001

62. Guba E, Lincoln S. Competing paradigms in qualitative research. In: Denzin NK, Lincoln YS, editors. Handbook of Qualitative Research, London, Thousand Oaks, New Delhi: Sage; 1994. p 105-18 
63. Charmaz K. Grounded theory: Objectivist and constructivist methods. In: Denzin N, Lincoln Y, editors.

Handbook of qualitative research. $2^{\text {nd }}$ ed. London: Thousand Oaks, New Delhi: Sage; 2000

64. Charmaz, K. Constructing grounded theory: A practical guide through qualitative research. London, Thousand Oaks, New Delhi: Sage; 2006

65. Charmaz, K. (2008). Constructionism and the grounded theory method. In: Holstein J, Gubrium J, editors. Handbook of Constructionist Research. New York: The Guilford Press; 2008

66. Charmaz, K. Shifting the Grounds. In: Morse J, Noerager P, Stern J, Corbin B, Bowers K, Charmaz, K, Clarke AE, editors. Developing grounded theory: The Second Generation. Walnut Creek, CA: Left Coast Press; 2009

67. von Tetzchner S, Basil C. Terminology and notation in written representations of conversations with augmentative and alternative communication. Augment Altern Commun 2011;27:141-49

68. Hynan A. Listening to adolescents who use AAC: Topics around social participation. Communication Matters National conference; 2011 Sept 25-27; Leicester. Edinburgh: Communication Matters 2011a

69. Hynan A. "How I use the Internet and online social media": Experiences of young people who use AAC. 15th biennial conference of the international society of augmentative and alternative communication; 2012 Jul 28 - Aug 4; Pittsburgh. Toronto: ISAAC 2012a

70. Hynan A. How I use the Internet and online social media: Experiences of young people who use AAC. Communication Matters National conference; 2012, Sept 15-17; Leicester. Edinburgh: Communication Matters 2012b

71. Hynan A. "How I use the Internet and online social media": Findings from a pilot investigation with an AAC user. Commun Matters 2011b;25:29-32

72. Hynan A. How I use the Internet and online social media: Experiences of young people who use AAC. Commun Matters;2013;27:10-12

73. Hulme, M. Life support: Young people's needs in the digital age. London: YouthNet; 2009

74. Helseth S, Misvaer N. Adolescents' perceptions of quality of life: what it is and what matters. J Clin Nurs 2010;19:1454-61

75. Ellcessor, E. Access ability: Policies, practices, and representations of disability online [dissertation]. University of Wisconsin-Maddison. 2012

76. Chapple D. The evolution of augmentative communication and the importance of alternate access. Perspect Augment Altern Commun, 2011;20:34-7 
77. Naslund R, Gardelli A. 'I know, I can, I will try': youths and adults with intellectual disabilities in Sweden using information and communication technology in their everyday life. Disabil Soc 2013;28:28-40

78. Seale J, Draffan EA, Wald M. Digital agility and digital decision-making: conceptualising digital inclusion in the context of disabled learners in higher education. Stud High Educ 2010; 35:445-461

79. Newell AF. Commentary on "Computers and people with disabilities": Accessible computing - past trends and future suggestions. ACM Transact Accessib Comp 2008; 1:9.1-9.7

80. Chantry J, Dunsford C. How do computer assistive technologies enhance participation in childhood occupations for children with multiple and complex disabilities? A review of the current literature. Brit J Occup Ther 2010; 73:351-365

81. Macdonald SJ, Clayton J. Back to the future, disability and the digital divide. Disability and society, 2012;28:702-718. http://dx.doi.org/10.1080/09687599.2012.732538. Accessed 2013 May 23

82. Fager S, Beukelman DR, Fried-Oken M, Jakobs T, Baker J. Access interface strategies. Assist Technol: The official journal of RESNA 2012;24:25-33

83. Hollier S. Sociability and social media for people with a disability. Report for Media Access Australia. 2012. http://www.scribd.com/doc/147567201/2012-Hollier-Access-Report-on-Social-Media-Australia. Accessed 2013 Feb 02

84. Hall L, Wreford S. National survey of care workers. Final report. TNS UK Ltd [online pdf] 2012. http://www.skillsforcare.org.uk/publications/national_publications_archive.aspx. Accessed 2013 ed Aug 15

85. Clayton J, Macdonald SJ. The limits of technology. Inform Commun Soc. 2013;16:945-966.

86. Smith MM. Literacy and augmentative and alternative communication. Boston: Elsevier Academic Press; 2006

87. Raghavendra P, Grace E, Newman L, Wood D, Connell T. 'They think I'm really cool and nice' The impact of Internet support on the social networks and loneliness of young people with disabilities. Telecommun J Aust 2013;63:22.1-22.15

88. Horton R, Horton K, Meyers L. Getting the literacy and language skills needed for employment: Teaching is the solution. In: Conti RV, McGrath III TJ editors. Proceedings of the 8th annual Pittsburgh conference for augmented communicators, Aug 10-12 2001. Pittsburgh, PA: Shout Press 2001; p 46-51

89. Beukelman D, Mirenda P. Augmentative and alternative communication: Supporting children and adults with complex communication needs 3rd edition. Baltimore, MD: Paul H Brookes Publishing; 2005 
90. Milner P, Kelly B. Community participation and inclusion: People with disabilities defining their place.

Disabil Soc 2009;24:47-62

91. Smith MM, Murray J. Parachute without a ripcord: The skydive of communication intervention. Augment Altern Commun 2011;27:292-303

92. Duckett N. Asian work choices: how AAC can liberate the user. Disabil Rehabil: Assist Technol, $2010 ; 5: 236-239$

93. Zhao S, Grasmuck S, Martin J. Identity construction on Facebook: Digital empowerment in anchored relationships. Comp Hum Behav 2008;24:1816-36

94. Bowker N, Tuffin K. Disability discourses and online identities. Disabil Soc 2002;17:327-344

95. Clarke M, McConachie H, Price K, Wood P. Views of young people who use augmentative and alternative communication systems. The Int J Lang Comm Disord 2001;36:107-15

96. Tavares, L. and Peixoto, A. (2003). Late development of independent conversation skills with manual and graphic signs through joint activities. In: von Tetzchner S, Grove N, editors. Augmentative and alternative communication: Developmental issues. London: Whurr Publishers; 2003.

97. Ballin L, Balandin S. An exploration of loneliness: Communication and social networks of older people with cerebral palsy. J Intellect Dev Disabil 2007;32:315-27

98. Cooper L, Balandin S, Trembath D. The loneliness experiences of young adults with cerebral palsy who use alternative and augmentative communication. Augment Altern Commun 2009;25:154-64

99. Runswick-Cole K, Goodley D. Resilience: a disability studies and community psychology approach. Soc Personali Psychol Compass, 2013;7:67-78

100.Whitty M. Liberating or debilitating? An examination of romantic relationships, sexual relationships and friendships on the net. Comp Hum Behav, 2008;24:1837-50

101.Mahar A, Cobigo V, Stuart H. Conceptualizing belonging. Disabil Rehabil:2013;35:1026-32

102.Hynan A. How I use the Internet and online social media: Experiences of young people who use Augmentative and Alternative Communication (AAC) [dissertation]. Manchester, UK: Manchester Metropolitan University; 2013. Available from: http://www.e-space.mmu.ac.uk/e-space/ [last accessed 22 Nov 2014]

103.Hynan A, Murray J, Goldbart J. 'Happy and excited': Perceptions of using digital technology and online social media by young people who use augmentative and alternative communication. Child Lang Teach Ther 2014;30:175-86

Hynan, A., Goldbart, J. \& Murray, J. (2015). A grounded theory of Internet and social media use by young people who use augmentative and alternative communication (AAC). Disability and Rehabilitation, early online. DOI 10.3109/09638288.2015.1056387 
Hynan, A., Goldbart, J. \& Murray, J. (2015). A grounded theory of Internet and social media use by young people who use augmentative and alternative communication (AAC). Disability and Rehabilitation, early online. DOI 10.3109/09638288.2015.1056387 